\title{
El arte plástico que no es elástico
}

Noel Castro

Según la etimología, los términos plástica y plástico tienen origen griego; pero del latín, plastica transmite las ideas de "arte de plasmar, o formar cosas de barro, yeso, etc.”; y plasticus: 1) perteneciente o relativo a la plástica, y 2) capaz de ser modelado. ${ }^{1}$

Siendo esto así, el conocido como "arte puro" o "no utilitario" en la pintura en particular, y en el arte gráfico en general, tiene que ser flexible pero definido en todos sus aspectos. De ahí que sea plástico. Esto incluye la escultura, el tallado, las 'instalaciones' (entre comillas porque no se refieren a las eléctricas normales, por ejemplo, aunque se use la electricidad en ellas) y todo lo que resulte ser una expresión material de la creatividad, de la necesidad y del pensamiento humanos.

Es interesante que esa flexibilidad llegue a tener una forma completa, final, un concepto bien definido, aunque sea solo para el artista, pues las percepciones que puedan tener los observadores de la pieza o de la muestra artística pueden ser tan variadas como se les ocurran a cada uno. Aquí es donde entra el discurso o teoría, que trata de explicar la intención del arte en sí. Solo entrar a un museo o a una galería de arte y ver la obra de los artistas sin meditar y reflexionar en su, o sus, significado, al parecer no cumpliría la función educativa o cultural del quehacer humano artístico. Aunque también eso depende del valor intrínseco de la obra y de la trayectoria del artista, sin mencionar la latitud de donde nació, cosa esta última que pudiera no tener la mayor importancia.

En esto es donde no cabe el término elástico en el arte ("que puede recobrar más o menos completamente su forma y extensión tan pronto como cesa la acción que las alteraba", "acomodaticio, que puede ajustarse a muy distintas

1 La citas etimológicas son del diccionario de la Real Academia de la Lengua. 
circunstancias"), porque se da a entender que la obra puede ser llevada a sus extremos y volver a su forma original o a la que el observador o el crítico la quieran llevar. Eso es algo inusitado. Pero así es el asunto: a veces con el discurso, o "lectura" - como se suele llamar al esfuerzo de comprender o asimilar una o varias obras - es que se 'logra' eso, solo de manera conceptual, porque el trabajo en observación no pasa de ser lo mismo: una obra terminada. Algunas esculturas las han hecho móviles, pero no pasan de allí.

Veamos un breve acercamiento, por medio de comentarios generales, a la obra de un artista francés del siglo XIX muy connotado.

Ya en sus cuadros de época temprana se entregó Monet - en mayor medida aún que sus amigos de la escuela impresionista - a la percepción de un estado de ánimo instantáneo. [...] Monet era rápido, fugaz, parecía tener siempre prisa, hizo suya la creciente premura y el ritmo de las grandes metrópolis. Su gran aportación sigue siendo la constante profundización de esta mirada, de manera que no solo se correspondía con la batahola que inundaba el Bulevar de los Capuchinos, sino que fue capaz también de captar una imagen de la naturaleza que él sentía como un constante proceso, y que por ello se halla en constante mutación. ${ }^{2}$

¿Sería que así pensaba el maestro de su obra y que esa fuera su intención? De hecho, el arte de Monet no era 'elástico'. Y su interpretación se puede hacer desde sus temáticas y técnicas plásticas, y tomando como base el estudio y los discursos que se presenten de su exhaustivo trabajo, porque sin duda fue un genio de la pintura y de la escuela llamadas impresionistas. Además, pocos son los que tienen la oportunidad visitar los museos donde se encuentran sus obras para hacer estudios y sacar conclusiones con más pruebas de autenticidad.

De modo que el pintor, o artista plástico, al dar muchas explicaciones de su obra terminada no le añadirá valor o - por decirlo así - transformación alguna a lo hecho. Esto no quiere decir que no pueda hacerle cambios a su obra cuanto lo crea conveniente; pero la tiene que terminar. Unas veces el comentario expresado, sea hablado o escrito, no pasa de ser una comprometida admiración; otras, los entendidos solo le tienen "simpatía" a la pieza, sin añadirle ningún otro "valor".

2 Schmied, Wieland, "Claude Monet y el arte moderno' en la Hypo-Kunsthalle de Munich”, KULTURCHRONIK, No. 1, 2002 (Año 20) 
En esta misma línea de pensamiento viene esta reflexión:

Porque en arte la anécdota es lo de menos. Es el medio de expresión de un valor estético, que es decir también un valor humano: el dolor, el odio, el amor, la duda... La anécdota se crea - mejor dicho, se recrea - con temas reales y vivos, elegidos ordenados, depurados, para que en ellos se exprese ese valor estético con toda su fuerza y pureza. Y lo que llega a nosotros no es la historia, sino el valor puro que se expresa mediante ella. Por eso no importa que sea desconocida y lejana. La anécdota en sí es inoperante, inerte. Lo que actúa y vive es el valor que significa. Eso es el arte puro. ${ }^{3}$

¿A qué artistas o maestros de la plástica salvadoreña les aplican estas apreciaciones? Este interrogante solo es retórico, porque en realidad y cabalmente no se puede responder. Siempre existen discrepancias en las opiniones o "juicios" vertidos frente a las obras e los pintores o cultores de las otras ramas del arte visual.

Con todo, se aspira a que el trabajo artístico sea auténtico. Parafraseando las palabras Jeanine Janowsky, 'la obra debería ser una suerte de autorretrato del artista'; si es sincero con su quehacer sostiene siempre ella. Es indiscutible que el verdadero arte plástico es digno de aprecio y tiene su precio. Lo del mercado es otro asunto.

Y para concluir, leamos unas líneas que transmiten el ánimo de la coleccionista Ingvild Goetz - que también podría ser el de los galeristas o de los museos institucionales del país - acerca de su singular museo de arte:

Esta coleccionista habla de su Museo como de un buen amigo, por cuya salud y bienestar está ella profundamente interesada, y que por otra parte le proporciona continuamente nuevas fuerzas. [...] El edificio, que causa una impresión de transparencia y de una ingravidez debido a su zócalo de vidrio opalino, colocado de forma plana al margen e un bosquecillo de abedules, encanta a los freaks de la arquitectura y entusiasma a los apasionados por el arte como sede ideal para una colección de tal categoría, que como pocas en su género está - con valentía y curiosidad absolutas - a la altura de su tiempo. ${ }^{4}$

3 Villegas López, Manuel, Charles Chaplin, el genio del cine, España, Editorial ABC, S.L., 2003.

4 Schmied, Wieland, “'Claude Monet y el arte moderno' en la Hypo-Kunsthalle de Munich”, KULTURCHRONIK, No. 3, 2001 (Año 19)

4 Schmied, Wieland, “'Claude Monet y el arte moderno' en la Hypo-Kunsthalle de Munich”, KULTURCHRONIK, No. 3, 2001 (Año 19) 


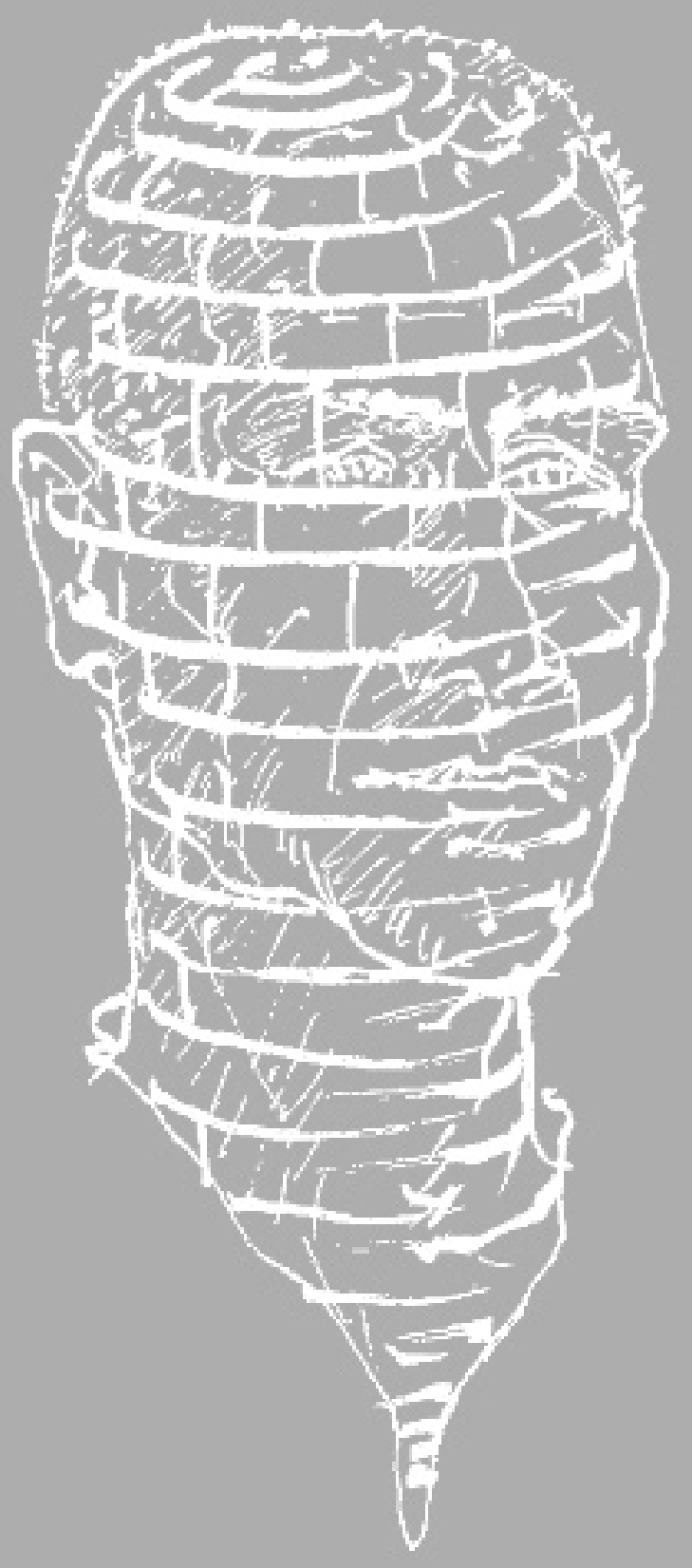

